\title{
A TESSITURA DA MULHER-PROFESSORA EM UMA NARRATIVA AUTOBIOGRÁFICA DO BRINCAR DA CRIANÇA COM DEFICIENNCIA.
}

\author{
Simone de Paula Rocha Souza \\ Mestranda do Progama de Pós-Graduação em Educação do Campus Universitário de \\ Rondonópolis da Universidade Federal de Mato Grosso. Professora da Secretaria \\ Estadual de Educação do Estado de Mato Grosso (SEDUC/MT). \\ mone_rocha7@hotmail.com
}

resumo: Neste artigo tenciono discutir sobre o silenciamento da mulher em uma sociedade patriarcal, da criança com deficiência em uma sociedade normatizada e pensar sobre o processo do brincar em suas relações com a educação. Como ocorreu o processo de emancipação, ou tentativa desta, em minha busca como mulher no espaço público? Como se constitui a professora tecelã de uma educação de sensibilidade e o brincar da criança com deficiência? Desse modo, sob a perspectiva metodológica da narrativa autobiográfica, busco discutir os enfrentamentos que demarcam as diferentes interfaces da mulher-professora do Atendimento Educacional Especializado. Trata-se de pesquisa em andamento, cujos resultados apontam que a criança com deficiência também brinca e se expressa num diálogo constante com o Outro.

palauras-chave: Autobiografia. Mulher. Professora. Criança com deficiência. Brincar. abstract: In this article I intend to discuss the silencing of the woman in a patriarchal society, of the child with deficiency in a standardize society and think about the process of playing in its relations with education. How has the process of emancipation, or an attempt of it, occurred in my search as woman in the public space? How is it constituted a teacher weaver of an education of sensibility and the playing of the child with deficiency? Therefore, through the methodologic perspective of the autobiographic narrative, I seek to discuss the confrontation which distinguishes the different interfaces of the woman-teacher of the Specialized Educational Service. It is a research in progress, of which the results point out that the child with deficiency also plays and expresses itself in a constant dialogue with the Other.

key-words: Autobiography. Woman. Teacher. Child with deficiency. Playing. 
Ele tinha no rosto um sonho de ave extraviada.

Falava em língua de ave e de criança. Sentia mais prazer de brincar com as palavras do que de pensar com elas.

Dispensava pensar

Quando ia em progresso para árvore queria florear. Gostava mais de fazer floreios com as palavras do que de fazer ideias com elas. Aprendera no Circo, há idos, que a palavra tem que chegar ao grau de brinquedo

Para ser séria de rir.

Contou para a turma da roda que certa rã saltara sobre uma frase dele

E que a frase nem arriou.

De ouvir o conto da rã na frase a Dona falou: Isso é Língua de brincar e é idiotice de criança

Pois frases são letras sonhadas, não têm peso, nem consistência de corda para aguentar uma rã em cima dela Isso é língua de Raiz - continuou E Língua de Faz-de-conta E Língua de brincar! Manoel de Barros, Toda Poesia.

\section{introdução}

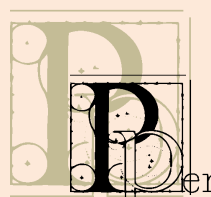

pessoal do narrador é experienciar o que me atravessa enquanto pessoa e compartilhar os saberes que me constituem ao longo da jornada, no processo do (re)fazer-me continuamente. Como referenda Larrosa1" "a experiência é o que nos passa, o que nos acontece, o que nos toca. Não o que se passa, não o que acontece, ou o que toca". Para vivenciar experiências com a densidade que o autor traz, é necessário tempo para que as experiências se interpenetrem em mim, como fíos nas mãos de uma tecelã: assim é o "saber da experiência".

1 LARROSA, Jorge. B. Notas sobre a experiência e o saber de experiência. In: Revista Brasileira da Educação. $n^{\circ}$. 19, Jan/Fev/Mar/Abr, Rio de Janeiro: ANPED, 2002, p. 21.

SoUza. Simone de Faula rocha. A tessitura da mulner-professora em uma narrativa autobiošráfica do brincar da eriança com deficiência.

alouquerque: revista de nistória. val. 10, no 19. jan.-jul. de 2018. p. $178-194$. 
Compreendo que a narrativa autobiográfica, para além de meu relato pessoal, permite trazer visibilidade às experiências que me atravessaram enquanto mulher e professora. São os processos dessas aprendizagens que me constituem enquanto pessoa, pois, como lembra Larrosa ${ }^{2}$, essas experiências, de modo singular e único, atravessam a todos nós. São os saberes da experiência capazes de configurar uma visão do mundo, dando sentido ao estar no mundo, e de estabelecer uma relação dialógica com as demandas que envolvem o ser mulher e professora de crianças com deficiência.

Trata-se da maneira singular como vivi (e vivo), experimentei (e experimento) a minha constituição de professora na educação especial. Compreendo, aqui, a narrativa autobiográfica como um elemento disparador para uma consciência emancipatória: "É assim que o paradigma do singular-plural junto com o paradigma experiencial e com o paradigma do Sensível, criam as condições de uma fecundação mútua"3. Um processo de reflexão e reconhecimento de aprendizagens capazes de redefinir meu modo de pensar e agir coletivamente.

A presente narrativa autobiográfica tenta romper com $\circ$ binarismo homem/mulher, normal/anormal e me permitirá ir para além da vivência. As narrativas evocadas são um exercício de reconhecimento dessas mulheres presentes em minhas memórias, "penso que pelo fío da memória e pelo ato de narrar-se [.]. provocamos pontes, diálogos e partilhas"4. É uma forma de me relacionar com o mundo, como apontam Josso e Pozzer ${ }^{5}$ desenvolvendo características e maneiras de estabelecer essas relações com o outro, (re)significando-me.

Em se tratando da relevância das narrativas autobiográficas, Passeggi, Abrahão e Delory-Momberger ${ }^{6}$ destacam que "Traduzir a vida em palavras promete ao narrador obter, contra o risco de se expor, o benefício de clarificar suas atitudes

\footnotetext{
2 Ibidem, 2002.

3 JOSSO, M. C.; POZZER, A. Fecundação mútua de metodologias e de saberes em pesquisa-formação experencial. Observações fenomenológicas de figuras do acompanhamento e novas conceituações. In: PASSEGI, Maria da Conceição; ABRAHÃO, Maria Helena Menna Barreto (org.). Dimensões epistemológicas e metodológicas da pesquisa (auto)biográfica. Tomo I. Natal: EDUFRN; Porto Alegre: EDIPUCRS; Salvador: EDUNEB, 2012, p. 114. Coleção Pesquisa (Auto)Biográfica: temas transversais.
}

${ }^{4}$ BERNARDES, R. K. Narrativas estéticas na docência: em nós - mãos. In: MONTEIRO, Filomena de Arruda; NACARATO, Adair Mendes; FONTOURA, Helena Amaral da (org.). Narrativas docentes, memórias e formação. Curitiba: CRV, 2016, p. 171.

5 Ibidem.

${ }^{6}$ PASSEGGI, M. da C.; ABRAHÃO, M. H. M. B.; DELORY-MOMBERGER, Christine. Reabrir o passado, inventar o devir: a inenarrável condição biográfica do ser. In: PASSEGI, Maria da Conceição; ABRAHÃO, Maria Helena Menna Barreto (org.). Dimensões epistemológicas e metodológicas da pesquisa (auto)biográfica: Tomo II. Natal: EDUFRN; Porto Alegre: EDIPUCRS; Salvador: EDUNEB, 2012, p. 40. Coleção Pesquisa (Auto)Biográfica: temas transversais, p. 32-40.

\footnotetext{
SoUza. Simone de Faula hocha. A tessitura da mulner-professora em uma narrativa autobiošráfica do brincar da eriança com deficiência.

albuquerque: revista de história. val. 10, no 19. jan.-jul. de $2018.0 .178-194$.
} 
e decisões e, sobretudo, o mérito de aprender a compor versões suficientemente boas de si para melhor agir no mundo".

Escrever em uma perspectiva autobiográfica é considerar-me como sujeito do processo de construção social, de minha subjetividade, em uma troca incessante com as íntimas conviç̧ões com que me deparo, numa tentativa de responder a um profundo e provocador questionamento: "Quantos de nós aceitamos o desafio de explorar o desconhecido? $\bigcirc$ desconhecido dentro de nós:?"7

Narrar a partir desses lugares é também problematizar e indagar-me. Será que meu olhar para a infância se transformou, democratizou-se? Ou ainda concebo a criança como patrimônio sob o domínio do adulto, em uma visão conservadora e patriarcal? Como efetivar essa travessia de dentro para fora? De dentro desses valores enraizados em mim pela cultura vivida; para fora, para esse outro, essa criança constituída por suas especificidades de ser e estar no mundo.

Ao concebê-la como pessoa, ainda se faz necessário questionar: que pessoa é essa? Para Ferreira-Santos ${ }^{8}$ a palavra pessoa, no grego, tem várias acepções, mas tem uma com a qual ele trabalha e que direciona o meu texto: "Prósopon, aquele que afronta com sua presença". Meu olhar para infância e para o brincar transcendeu? A inclusão se efetivou? Vivo com a falsa impressão de que aspiro novos ares. Entretanto, ao pensar sobre este lugar do Outro, é preciso:

Perceber que o Outro, o diferente, não deve ser julgado nem avaliado pelos atributos que são nossos, tendo-se, portanto, como termo de comparação precisamente aquilo que temos e que "falta" ao Outro. A percepção dessa "falta" é a forma de tentarmos submeter ao controle racional a sombra em que o Outro diferente se constitui para nós?.

Essa percepção do Outro como o diferente que merece igualdade é que foì me tornando a mulher que hoje sou.

\footnotetext{
${ }^{7}$ WILLMS, E. E.; ALMEIDA, R.; FERREIRA-SANTOS, M. A pesquisa como jornada interpretativa: uma leitura metafórica do filme "A lenda do pianista do mar". 2014, p. 127. Disponível em: https://repositorio.unp.br/index.php/quipus/article/download/700/486. Acessado em: maio de 2018.

${ }^{8}$ FERREIRA-SANTOS, M. Crepusculário: conferências sobre mitohermenêutica \& educação em Euskadi. São Paulo: Zouk, 2004, p. 190.
}

9 FERREIRA-SANTOS, M.; ALMEIDA, R. Antropolíticas da Educação. São Paulo: Képos, 2014, p. 197, grifos dos autores.

SoUza, Simone de Faula kocha. A tessitura da mulner-professora em uma narrativa autobiošráfica do brincar da criança com deficiência.

alouquerque: revista de nistória. val. 10, no19. jan.-jul. de 2018. p. 178-194. 


\title{
memórias tecidas na trajetória e na história da mulher-professora
}

\author{
Os percursos de mulher e professora do Atendimento Educacional \\ Especializado 10 (AEE), neste binômio "singular-plural", ramificadas em uma única \\ constituição, me permitiram vivenciar experiências que revelam as potencialidades \\ da criança com deficiência e avançar no sentido do que a sociedade moderna pensa \\ sobre os "anormais":
}
[...] divididos nas cada vez mais numerosas categorias que a Modernidade tem incansável e incessantemente inventado: os sindrômicos, deficientes e psicopatas (em todas as suas variadas tipologias), os surdos, os cegos, os aleijados, os rebeldes, os pouco inteligentes, os estranhos, os "outros", o refugo enfim - podem, ou mesmo devem ser misturados, nas escolas, com os normais - cada vez mais parecidos com nós mesmos e, bem por isso, cada vez mais especiais, melhores, mais raros...' ${ }^{11}$

Essa "sociedade" não consegue conceber a criança com deficiência como pessoa, ela precisa de rótulos para normatizar a exclusão e revelar as impossibilidades que a deficiência deve impor à pessoa. É na contramão dessa visão que se constituem as minhas memórias de professora do AEE, numa perspectiva fenomenológica do brincar da criança com deficiência, numa abordagem de educação de sensibilidade. Trata-se de uma experiência radical em que se faz:

[...] a vivência de uma situação em que dois seres, educador e aprendiz, se encontrem, para além do diálogo verbal, dialoguem com seus corpos na situação concreta de uma experiência que os comunga, os coloca no horizonte da pessoalidade, [... imprevisto e incontrolável do viver com alguém-conviver-mediados pelo

10 O Atendimento Educacional Especializado (AEE) é um serviço ofertado nas escolas públicas para as crianças com necessidades especiais, espaço onde se elaboram e organizam recursos pedagógicos e de acessibilidade para favorecer e eliminar as barreiras das pessoas com necessidades específicas. Atuei como professora do AEE na Escola Estadual Vale do Guaporé, na cidade Pontes e Lacerda-MT, nos anos de 2015 e 2016.

11 VEIGA-NETO, A. Incluir para saber. Saber para excluir. Pro-posições, v. 12, n. 2-3 (35-36). jul.-nov. 2001, p. 23.

SuUza. Simone de Faula rocha. A tessitura da mulner-professora em uma narrativa autobiousráfica do brincar da criança com deficiência.

alouquerque: revista de inistória. val. 10, n.o19. jan.-jul. de 2018. p. 178-194. 
caráter existencial e corporal do "fazer juntos". Numa palavra experimentação. ${ }^{12}$.

Para entender como percorri meu caminho até en-cantar-me pelo fazer docente com as crianças com deficiência, faz-se necessário um breve recorte de minha infância, onde tudo começou. As aventuras de infância me fazem voltar no tempo e rememorar as experiências mais ricas e gratificantes de minha trajetória. Lembro Quintana1", ao recordar de "Estranhas aventuras da infância. Era um caminho tão pequenino. Que nem sabía aonde ia, por entre uns morros se perdía. Que ele pensava que eram montanhas". Foram nesses caminhos pequeninos, como bem escreve o poeta, em que muitas vezes me vi perdida, sem saber por onde andar. São essas lembranças de sentir que "nem sabia aonde ia", que me trazem novamente ao cenário de minhas brincadeiras de infância. Era nos morros do sul paranaense que "me perdia" por entre as serras a brincar com as canoas que caíam das palmeiras e que também serviam de balanço nas brincadeiras de rolar gramado abaixo. Para mim, tão miúda, envolta pela imensidão da paisagem fria, os morros pareciam as montanhas mais altas, que eu, em minha ingênua concepção, jamais imaginaria transpor.

Sim, eu brincava com toda minha essência de criança, como referencia Willms ${ }^{14}$, pois "brincar floresce a existência da criança. É todo um corpo que se experimenta, se enraíza e no movimento encontra, recolhe, investiga, indaga, vaí compreendendo, vivenciando e aprendendo o mundo: pelo brincar". Nesses corpos que se experimentam, diversos sentimentos e emoções vão constituindo o ser enquanto pessoa. As brincadeiras que propunha me mostravam a cada dia o delinear de minha trajetória. As indagações e curiosidades que me impulsionavam a mergulhar no desconhecido motivaram minhas escolhas, que já prenunciavam as nuances de um espírito investigativo e aventureiro, alimentado desde a infância.

Hoje sou capaz de compreender para além do prazer do brincar de casinha e bonecas, reconhecendo a relevância de:

${ }^{12}$ FERREIRA-SANTOS, M. Experimentação pelas creanças: a brincagogia sensível. São Paulo: Sidarta, 2008, p. 02. Projeto Aqui se Brinca. Disponível em: <http://www.marculus. net>. Acessado em: 14 de julho de 2017.

${ }^{13}$ QUINTANA, M. Baú de espantos. São Paulo: Globo, 2006.

${ }^{14}$ WILLMS, E. E. Escrevivendo: uma fenomenologia rosiana do brincar. Tese Doutorado - Programa de PósGraduação em Educação. Área de Concentração: Cultura, Organização e Educação. Faculdade de Educação da Universidade de São Paulo, 2013, p. 25.

SoUza. Simone de Faula rocha. A tessitura da mulner-professora em uma narrativa autobiošráfica do brincar da eriança com deficieiência.

alouquerque: revista de nistória. val. 10, no19. jan.-jul. de 2018. p. 178-194. 
[...] acompanhar seus percursos, descobrir suas preferências, se maravilhar com suas descobertas; se sensibilizar com suas dores, se encantar com seus saberes. Rolar com elas, brincar junto, pintar junto. Viver intervalos de suas vidas com elas e reviver os da nossa infância, em um voltar a ser criança por alguns instantes. ${ }^{15}$.

Percebo porque essa brincadeira ainda desperta meu interesse, a imersão em memórias que descortinam uma infância de descobertas e de saberes. Mas, para mais do brincar de casinha, estava minha paixão pelas brincadeiras de escolinha, em que adorava ser a professora. Hoje, mais do que nunca, penso ser desde essa época meu desejo pela profíssão docente, um pensamento que reverbera as palavras de Lispector 16: "se vocês gostam de escrever ou desenhar ou dançar ou cantar, façam porque é ótimo: enquanto a gente brinca assim, não se sente mais sozinha, e fica de coração quente". Esse era o sentimento que me completava quando não tinha companhia para brincar e me aventurava sozinha.

Rememorando minha infância, perdendo-me nos devaneios dos anos de cor azul, como era o cenário das diversas imagens que criava deitada na grama contemplando o céu, reverencio a fala de Bachelard17: "outros sonhos nascem ainda quando, em vez de ler ou de falar, escrevemos como se escrevia outrora, no tempo em que estávamos na escola". Sim, na escola... Lá também nascem sonhos! Foram desses sonhos e desejos, do encantamento pelo Outro, que nasceram minhas vontades ${ }^{18}$ de lutar por uma causa em minha caminhada docente, causa está que realmente despertasse em mim o que considero essencial como pessoa: a sensibilidade.

Era no cair lento da tarde que as brincadeiras ficavam ainda melhores, não sei se pelo tempo restante ser muito reduzido, ou porque realmente eram muito prazerosas. Quando podia reunir-me aos primos e deixar a imaginação me conduzir, eram tantas ideias que me reporto à personagem Raquel ${ }^{19}$, que escondia suas vontades nos bolsos da bolsa amarela: "Eu tenho que achar um lugar pra esconder

15 FRIEDMANN, A. O olhar antropológico por dentro da infância: adentrando nas casinhas das crianças. In: MEIRELLES, R. (Org.). Território do brincar: diálogo com as escolas. São Paulo: Instituto Alana, 2015, p. 44. Coleção Território do Brincar.

16 LISPECTOR, C. A mulher que matava os peixes. Rio de Janeiro: Rocco, 1999, p. 05.

17 BACHELARD, G. A poética do devaneio. São Paulo: Martins Fontes, 1988, p. 48.

18 A personagem Raquel, da obra A Bolsa Amarela, tentava sufocar suas vontades dentro de uma bolsa amarela, já que não poderia vivê-las, porque os adultos não entenderiam. Analogia feita por mim em relação à escolha profissional que fiz, em especial do trabalho com as crianças com necessidades específicas, incompreensível para muitos.

${ }^{19}$ BOJUNGA, L. A bolsa amarela. Rio de Janeiro: Agir, 1998, p. 11.

\footnotetext{
SoUza, Simone de Faula rocha. A tessitura da muliner-professora em uma narrativa autobiošráfica do brincar da eriança com deficiêneía.

albuquerque: revista de nistória. val. 10, no19. jan.-jul. de 2018, p. $178-194$.
} 
as minhas vontades." Muitas vezes, meu pai participava das brincadeiras, uma gente grande que se permitia brincar. Como eram indescritíveis esses momentos! Ainda bem que ele não compartilhava dos pensamentos do mundo adulto, tal como descrito por Raquel, de que "[..] gente grande tem mania de achar que porque é grande não pode mais brincar" (BOJUNGA) ${ }^{20}$.

\section{tenacidade e resistência: elementos das teias que me constituíram professora}

Dessas vontades de gente grande é que comecei meu trabalho com as crianças com Necessidades Educativas Especiais, experiências que me atravessaram enquanto pessoa, como referenda Larrosa ${ }^{21}$. Impossível sair ilesa das experiências que me atravessam, que me afetam. Existe uma professora antes dessas vivências e outra que nasce após. Diante desta constatação, assombro-me, tal como MerleauPonty ${ }^{22}$ : "A esse infinito que eu era, algo ainda se acrescenta, um rebento brota, desdobro-me, engendro, esse outro é feito de minha substância, e no entanto não é mais eu. Como isso é possível?".

Rememorar as brincadeiras de infância e vivenciá-las com meus alunos trouxe os mesmos aromas, sabores e cores daquela época. Deixar-me ser conduzida por elas nas brincadeiras mostrou-me o quanto preciso evoluir e aprender, aprender com o Outro. Como aponta Merleau-Ponty ${ }^{23}$, uma experiência de "ser uma consciência, ou, antes, ser uma experiência, é comunicar anteriormente com o mundo, com o corpo e com os outros, ser com eles em lugar de estar ao lado deles".

Dessa forma, ao pensar o brincar da criança com deficiência, é preciso primeiramente concebê-la como pessoa, como criança, não com um rótulo de preconceito que a segrega e a impossibilita de experienciar emoções que não lhe deveriam ser negadas como pessoa. Sendo assim, acredito que:

Sim, a brincadeira é a situação básica de experimentação das creanças ${ }^{24}$. E aqui o educador é também creança... criação continua de si mesmo, desde que aberto às aprendizagens que, de repente,

\footnotetext{
20 Ibidem, p. 11.

${ }^{21}$ Ibidem.

22 MERLEAU-PONTY, M. A prosa do mundo. São Paulo: Cosac \& Naify, 2002, p. 168.

${ }^{23}$ MERLEAU-PONTY, M. Fenomenologia da percepção. 2. ed. São Paulo: Martins Fontes, 1999, p. 142.

${ }^{24}$ Para Ferreira-Santos, criança como pessoa é uma criação contínua, inacabada, e, ao mesmo tempo, criadora e criatura, construção cotidiana de si mesma, creança.
}

\footnotetext{
SoUza. Simone de Faula rocha. A tessitura da mulner-professora em uma narrativa autobiošráfica do brincar da eriança com deficiêneía.

alouquerque: revista de inistória. val. 10, n.o19. jan.-jul. de 2018, p. 178-194.
} 
acontecem no jogo desinteressado da convivência. Haverá situação educativa mais profunda e mais significativa do que aprender-se e aprender o outro ensinando-se e sendo ensinado pela pessoa da criança? 25 .

Parto da compreensão de que a criança me conduz na brincadeira, é ela que me leva pelos caminhos que, na maioria das vezes, desconhecemos. Neste sentido, Freire $^{26}$ aponta para o diálogo como o "encontro com os homens, mediatízados pelo mundo, para pronunciá-lo, não se esgotando, portanto, na relação eu-tu”. Uma relação para além das impossibilidades que são apresentadas à criança com deficiência. É essa experiência do fazer juntos que me provocava a "reagir ao estranhamento causado pelo contato com as diferenças [e] obrigava-me a elaborar novos significados "27, configurando-se, assim, como um espaço profícuo para pensar o brincar da criança com necessidades especiais.

No entanto, Veiga-Neto ${ }^{28}$ enfatiza que "a própria organização do currículo e da didática, na escola moderna, foi pensada e colocada em funcionamento para, entre várias outras coisas, fixar quem somos nós e quem são os outros". Não há espaço para essa relação eu-tu como Ereire ${ }^{29}$ assinala, ou para "novos significados" como Willms ${ }^{30}$ sugere, pois, a norma preconiza um movimento de marcar a distinção da normalidade e da anormalidade. Nesse viés, fica evidente que na realidade, no enfrentamento cotidiano e na sala de aula existe um discurso adultocêntrico envolvendo não só a criança com defíciência, mas as creanças, expressando como a escola e o educador a veem. Portanto, compartilho a ideia de que,

No fundo, porém, os grandes arquivados são os homens, nesta (na melhor das hipóteses) equivocada concepção "bancária" da educação. Arquivados, porque, fora da busca, fora das práxis, os homens não podem ser. Educador e educandos se arquivam na medida em que, nesta destorcida visão da educação, não há criatividade, não há transformação, não há saber. Só existe saber na invenção, na reinvenção, na busca inquieta, impaciente,

\footnotetext{
${ }^{25}$ Idem, 2008, p. 03.

${ }^{26}$ FREIRE, P. Pedagogia do oprimido. 17. ed. Rio de Janeiro, Paz e Terra: 1987, p. 91.

27 Ibidem, p. 72.

28 Ibidem, p. 25.

29 Ibidem.

${ }^{30}$ Ibidem.
}

\footnotetext{
SuUza. Simone de Faula kocha. A tessitura da mulner-professora em uma narrativa autobiošráfica do brincar da eriança com deficieiência.

alouquerque: revista de nistória. val. 10, no19. jan.-jul. de 2018. p. 178-194.
} 
permanente, que os homens fazem no mundo, com o mundo e com os outros. Busca esperançosa também ${ }^{31}$

Nesta perspectiva é que compreendo a invenção ou a reinvenção desta busca esperançosa que Freire traz, como o sentido de exercitar o processo de desintoxicação da brincadeira como jogo pedagógico, sinalização para uma outra concepção de educação.

A provocação que Ferreira-Santos ${ }^{32}$ me instiga a perceber "a brincadeira, a experimentação das creanças, de maneira lúdica, livre e desinteressada para que possam exercitar essa busca de si mesma na descoberta do seu mundo interior na exploração do interior do mundo". A título de ilustração para esta fala, cito o brincar de peteca com um aluno com síndrome de Down, do Atendimento Educacional Especializado: enquanto "eu" educadora preocupava-me em "ensinar-lhe" como jogar peteca, ele, com a subjetividade inerente a cada pessoa, mostrou como a brincadeira pode seguir com as mais diferentes nuances, como um arco-íris após uma chuva: inesperado.

Assim, fiquei a observar como essa criança, com calma e curiosidade, explorou cada textura presente no brinquedo, as cores, os formatos de cada elemento, para só depois preocupar-se com o jogo. Hoje percebo que é assim que o brincar acontece: na invenção, reinvenção, na busca esperançosa de se constituir no mundo.

Discutir o brincar dessa criança na perspectiva de educação de sensibilitidade é percebê-la como pessoa desejosa de expressar-se e atuar na sociedade em que está inserida. $\dot{E}$ refutar as verdades impostas pela nossa cultura patriarcal, como assinalam Maturana e Verden-Zoller33, ao refletir que "vivemos na apropriação e agimos como se fosse legítimo estabelecer, pela força, limites que restringem a mobilidade dos outros em certas áreas de ação às quais eles tinham livre acesso antes de nossa apropriação".

brincar da criança com deficiência exige um olhar mais sutil, capaz de ultrapassar as lentes que minimizam as suas potencialidades e reconhecê-la como pessoa digna de ser acreditada ${ }^{34}$. Nesta ânsia de compreender a criança como pessoa

\footnotetext{
31 Idem, 2008, p. 66.

32 Ibidem, p. 04.

33 MATURANA, H. R.; VERDEN-ZOLLER, G. Amar e brincar: fundamentos esquecidos do humano do patriarcado à democracia. São Paulo: Palas Athena, 2004, p. 38.
}

${ }^{34}$ Do latim creditum, empréstimo, objeto entregue a alguém em confiança, de credere, crer, confiar.

\footnotetext{
SuUza. Simone de Faula rocha. A tessitura da mulner-prafessora em uma narrativa autobiošráfica do brincar da eriança com deficiêneía.

alouquerque: revista de história. val. 10, no 19. jan.-jul. de 2018. p. $178-194$.
} 
é necessário é preciso, ainda, "dar voz às crianças de modo a oportunizar tempos e espaços nos quais elas possam "falar, dizer, expressar-se" de forma espontânea, por meio de suas linguagens verbais e não verbais, seus sentimentos, percepções, emoções, momentos, pensamentos"35.

brincar possibilita à criança expressar suas angústias, seus medos e sua criatividade. Assim, no trabalho com a infância, faz-se necessário ajustar constantemente o foco de minha lente, substituir as certezas que construí ao longo de minha trajetória docente pela confiança que a criança precisa receber, pois creio, como lembra Freire", que o "o educador já não é o que apenas educa, mas o que, enquanto educa, é educado, em diálogo com o educando que, ao ser educado, também educa".

Educar, na perspectiva que Freire defende, é uma via de mão dupla. Minha luta pela criança com deficiência não é de hoje, é uma militância que transpassa minhas entranhas desde minha constituição enquanto pessoa, ou seja, desde sempre. Ao assumir o concurso público do Estado de Mato Grosso no ano de dois mil, iniciei como docente de uma turma de terceiro ano do Ensino Fundamental, e, naquela época, minha experiência como professora era ainda muito pequena, pois só tinha trabalhado por um curto período de tempo em uma escola privada e alguns meses na rede pública, em contrato temporário. Todavia, as experiências que me "passam" e que me transformam enquanto pessoa não escolhem tempo ou lugar para acontecer. Desse modo, logo no meu primeiro ano de atuação comecei minha profissão com um aluno com surdez.

Não se falava muito em inclusão, quase duas décadas atrás, o que fez com que eu me sentisse sozinha diante de tal tarefa. Ao lembrar desse período, ancorome nas palavras de Veiga-Neto", de que é "preciso ter sempre claro que mesmo aquilo que parece ocorrer apenas no âmbito escolar pode ter - e, quase sempre, tem - ligações sutis e poderosas com práticas (discursivas e não-discursivas) que extravasam a própria escola". Na verdade, embora se insista em dizer que não se falava em inclusão, as crianças estão há muito tempo gritando por seu espaço, nas práticas de oclusão "sutís e poderosas". Vale salientar que a escola não estava preparada, então, para receber as crianças com suas especifícidades, e ainda não está plenamente capacitada para isso.

\footnotetext{
35 Ibidem, p. 40.

36 Ibidem, p. 79.

37 Ibidem, p. 24.
}

\footnotetext{
SoUza. Simone de Faula nocha. A tessitura da muliner-professora em uma narrativa autobiošráfica do brincar da eriança com deficiêneia.

albuquerque: revista de história. val. 10, no 19. jan.-jul. de 2018. p. 178-194.
} 
Como argumenta Skliar ${ }^{38}$ "as fronteiras da exclusão aparecem, desaparecem e voltam a aparecer, se multiplicam, se disfarçam; seus limites se ampliam, mudam de cor, de corpo, de nome e de linguagem". São essas fronteiras que insistem em estar a serviço das normas, estabelecendo as diferenças, logo, para que eu estabeleça meu lugar, preciso dizer quem o outro é. Ele é diferente de mim, portanto, segundo o que a normatização evidencia, eu sou normal e esse outro é anormal, não diferente de mim, mas anormal

São essas fronteiras que excluem, mudam de cor, de corpo e de nome, mas continuam a excluir, porque, dessa forma, não é preciso mudar as relações de poder que já foram instituídas pela sociedade, onde cada um tem o seu lugar, a sua identidade. E lá estava meu aluno, no lugar da segregação disfarçada de inclusão. Estava sim na escola, no entanto, que espaço ocupava naquela comunidade escolar? Tinha seus anseios e direitos, como os ditos "normais", assegurados? Ou simplesmente a camuflagem da inclusão se escondia na penumbra da exclusão que ele vivia como pessoa? É ainda Skliar que problematiza:

A alteridade deficiente é um exemplo da voracidade com que o mundo moderno, sem soluções, inventa e exclui a esses outros. $\bigcirc$ lugar no mundo dos outros deficientes tem sido permanentemente relacionado e confundido com seu lugar institucional, e seu lugar institucional foi frequentemente profanado pela perversidade de pensá-lo todo nos termos estreitos de inclusão/exclusão ${ }^{39}$.

Foì como um grande desafio que se constituiu para mim aquele ano, tudo novo em minha vida, trabalhando em uma escola de periferia onde as questões sociais emergiam intensamente. Como contribuir em uma comunidade tão desassistida, especialmente no tocante ao atendimento às crianças com deficiência? Tais indagaçães pairavam no silêncio e na mordaça da inclusão/exclusão das políticas públicas da educação especial, inquietando-me profundamente, à medida que assimilava a complexidade do ensinar.

Nesse emaranhado de retalhos minha trajetória se costurava e nessa tessitura, as histórias mais incríveis iam sendo escritas. Não tinha formação inicial para assegurar o mínimo para esse aluno com surdez, tão pouco formação

${ }^{38}$ SKLIAR, C. A invenção e a exclusão da alteridade "deficiente" a partir dos significados da normalidade. Revista Educação e Realidade. Dez. 1999, p. 16.

${ }^{39}$ Ibidem, p. 16.

\footnotetext{
SoUza. Simone de Faula nocha. A tessitura da muliner-professora em uma narrativa autobiošráfica do brincar da eriança com deficiêneía.

albuquerque: revista de história. val. 10, no 19. jan.-jul. de 2018. p. 17z-194.
} 
continuada, contudo, a convicção de que ele era capaz de se comunicar e aprender me impulsionava a acreditar naquele menino. A expressão em seu rosto, sua alegría e vontade de aprender se constituíram como elementos essenciais em seu processo escolar.

Eu não tinha domínio ainda, da Língua de Brasileira de Sinais (LIBRAS) como forma de comunicação entre e com as pessoas com surdez e, consequentemente, não sabia como ultrapassar essa barreira na comunicação com meu aluno. Entretanto, é fundamental que seja dado "o primeiro passo numa operação de ordenamento, pois é preciso a aproximação com o outro, para que se dê um primeiro (re)conhecimento, para que se estabeleça algum saber, por menor que seja, acerca desse outro"40. $O$ primeiro passo estava dado, concretizado no fato de que pensar em inclusão é pensar nesse outro que também me constitui.

Para minha surpresa, no decorrer do processo a interação e a oportunidade de estar no mesmo espaço com todas as crianças possibilitou a este aluno avanços em sua aprendizagem. $O$ que mais me impressionava era a dissipação das barreiras no momento do brincar, mostrando que os limites/exclusões vivenciados pelas crianças com deficiência no processo escolar, podem, na maioria das vezes, ser extintos pela brincadeira, pois

\begin{abstract}
São muitos os universos que a criança cria em suas imagens de inteireza, integralidade. Universo de habitar, de encaixar-se, de resignar-se a viver. Poderíamos falar de brinquedos silentes, brinquedos do tempo, brinquedos de resignação, brinquedos de alteridade brinquedos de resiliência, brinquedos de comicidade. Todas essas virtudes do brincar têm seu embrião na imaginação de intimidade. ${ }^{41}$.
\end{abstract}

São esses os universos capazes de derrubar a muralha da exclusão, é nesse habitar, resignar-se nas mais diversas expressões do brincar que a criança consegue se ver no Outro. Como assevera Skliar", em "uma época de guerras virtuais e de pobrezas reais, onde o discurso sobre os outros, sobre a alteridade, adquire novos significados", pode-se vislumbrar, através do brincar, uma possibilidade de ir para

\footnotetext{
40 Ibidem, p. 26.

41 PIORSKI, G. Brinquedos do chão. São Paulo: Petrópolis, 2016, p. 29.

42 Ibidem, p. 16.
}

\footnotetext{
SuUza, Simone de Faula rocha. A tessitura da muliner-professora em uma narrativa autobiošráfica do brincar da eriança com deficiência.

alouquerque: revista de nistória. val. 10, no19. jan.-jul. de 2018. p. 178-194.
} 
além do discurso verbal, do discurso que separa e pensar no discurso do corpo, um discurso que ajunta.

Dessa maneira, conforme Merleau-Ponty ${ }^{43}$, os sentidos e o próprio corpo "apresentam o mistério de um conjunto que, sem abandonar sua ecceidade e sua particularidade, emite, para além de si mesmo, significações capazes de fornecer sua armação a toda uma série de pensamentos e experiências".

Para muito além das guerras e da pobreza real, que vê a pessoa através de sua diferença e faz dessa diferença uma forma de estabelecer um lugar de pertencimento para o Outro, o brincar pode trazer outra perspectiva. São esses universos que Piorskit4 apresenta, nos quais a capacidade da criança de criar imagens, de integrar-se torna possível envolver o Outro ou envolver-se. Esta perspectiva carrega a esperança de pensar numa mudança de paradigma, romper com o lugar e com:

A presunção de que a deficiência é, simplesmente, um fato biológico e com características universais, deveria ser problematizada epistemologicamente. Nesse sentido, é necessário inverter aquilo que foì construído como norma, como regime de verdade e como problema habitual: compreender o discurso da deficiência, para logo revelar que o objeto desse discurso não é a pessoa que está em uma cadeira de rodas ou o que usa um aparelho auditivo ou o que não aprende segundo o ritmo e a forma como a norma espera, senão os processos sociais, históricos, econômicos e culturais que regulam e controlam a forma acerca de como são pensados e inventados os corpos e as mentes dos outros. ${ }^{45}$.

As crianças sabem muito bem como fazer isso, derrubam os preconceitos que a sociedade normatiza, abrem espaços para que os diferentes se integrem para que, juntos, formem um único corpo, o corpo que constitui a infância. "E por meu corpo que compreendo o outro, assim como é por meu corpo que percebo "coisas "'s".

\footnotetext{
43 Idem, 1999, p. 178.

44 Ibidem, 2016.

45 Ibidem, p. 18.

${ }^{46}$ Idem, 1999, p. 253, grifo do autor.
}

\footnotetext{
SuUza, Simone de Faula rocha. A tessitura da muliner-professora em uma narrativa autobiošráfica do brincar da eriança com deficieiencia.

alouquerque: revista de nistória. val. 10, no19. jan.-jul. de 2018. p. 178-194.
} 
Refletir sobre estas concepções de diferença, sob a ótica da educação de sensibilidade trazida por Ferreira-Santos ${ }^{47}$, dialógica, como lembra Freire (1987), é deixar-se mergulhar. Esta analogia relaciona-se à beleza das águas límpidas de um riacho escondido entre rochosas montanhas: um percurso difícil, mas que traz a promessa do prazer inenarrável que se sente ao encontrá-lo. E na fusão dessas concepções, o brincar aparece-me como um caminho. Willmss ${ }^{48}$, ao referenciar o brincar, expõe as possibilidades inesgotáveis que se apresentam no sentido de perceber que as múltiplas aberturas e a curiosidade das crianças "podem encorajar e sustentar os professores nessa pedagogia do arriscar-se. Basta que o professor dê o primeiro passo, ensaie o primeiro gesto: um tantinho de liberdade, algumas possibilidades de escolha e abertura para o diálogo".

Também assim, penso eu, a brincadeira permeia o universo da criança com deficiência, quando esta, em seu mergulho no brincar, empreende uma viagem complexa, um experienciar de modo subjetivo, compartilhando ou não, as experiências que a constituirão como pessoa. Neste viés Ferreira-Santos, com maestria, elucida:

\begin{abstract}
Acreditamos que educar o olho para enxergar as flores e o céu, assim como educar a mão para cultivá-los (céu, flores e amigos) seja a divisa mais importante no mundo da Cultura, no seu sentido mais agrário: rasgar o solo árido, revolver a terra, plantar a semente, irrigar com um pouco de poesia e partir para outros campos, pois para o educador que aspira a ser uma sombra do didáskalos, [...] não se espera a pequena planta crescer. Terminado o plantio, segue para outros campos, pois o trabalho é imenso e sementes existem várias. ${ }^{49}$
\end{abstract}

Essa é a didática, que se espera do professor, que ele seja ao menos a sombra do didáskalos descrito pelo autor, a fim de possibilitar à criança com defíciência a brincadeira, a descoberta, o imaginário, sob a forma de creditum, de paixão, e aquí vou parafrasear Ferreira-Souza Santos ${ }^{50}$, só fará sentido se se deixar aflorar a paixão pelo outro. Cultivar expectativas e acreditar é o combustível capaz de mover a roda

\footnotetext{
${ }^{47}$ Idem, 2004.

48 WILLMS, E. E. A fonoaudióloga da tearte: experimentação vivencial pela brincadeira. Disponível em: https://repositorio.unp.br/index.php/quipus. Ano III, $\mathrm{n}^{\circ} 2$, jun./nov.2014, p. 49.

49 Idem, 2004, p. 46-47.

${ }^{50}$ Idem, 2008.

SoUza. Simone de Faula rocha. A tessitura da mulner-professora em uma narrativa autobiošráfica do brincar da eriança com deficiêneia.

albuquerque: revista de história. val. 10, no 19. jan.-jul. de 2018, p. 178-194.
} 
do amor. Esclarece o autor que a palavra "amor" "se compõe, em latim, pelo negativo "a" e pelo substantivo "mors" (morte). Portanto, o amor, em seu sentido etímológico é o apelo de vida (Eros) contra a morte (Thanatos), a não-morte, a não-paralisia, o nãoconformismo, a não-adaptação. $)^{51}$

\section{para concluir...}

É nesse caminho que estou a me constituir em e através de e por uma educação de sensibilidade, nesse sentido amoroso de cuidado para com a vída. Freire (1987, p. 91, grifo do autor) aponta nesta mesma direção ao afirmar que "Não é possível a pronúncia do mundo, que é um ato de criação e recriação, se não há amor que a infunda".

Assim, ao concluir este texto, em que falo do processo de me perceber e me conceber como mulher e professora, durante meus estudos na Pós-Graduação em nível de mestrado em Educação, educo meus olhos e todos os meus sentidos para notar os gestos mais sutis, os movimentos dos corpos que expressam uma história. Procuro um olhar sensível, mas ao mesmo tempo perspicaz, atento aos caminhos que as crianças vão delineando no cenário das brincadeiras. Educo-me como professora. É certo, também, que estou a rasgar a terra, rompendo com práticas e crenças tão arraigadas na sociedade e em mim, (re)fazendo-me, enquanto espero a "pequena planta crescer" - cada uma das crianças com deficiência que vaí florescendo à medida que recebe estímulo e confiança - vou crescendo à medida em que vou constituindo-me enquanto mulher, professora e como pessoa, sensível às experiências que me tocam, que me desafiam, mas que também me conduzem ao saber e ao sabor das experiências que todo esse campo proporciona. Escrever este texto autobiográfico foi uma maneira de compartilhar o que tenho aprendido nesta minha trajetória, de professora, mulher, trabalhadora. Essa tem sido a minha contribuição à Educação.

${ }^{51}$ Idem, 2008, p. 05. 